\title{
Ocupação e atividade: tendências e tensóes conceituais na literatura anglófona da terapia ocupacional e da ciência ocupacional
}

\author{
Lilian Magalhães
}

Doutora em Saúde Coletiva, Professora Associada, Western University of Ontario, Canadá

\begin{abstract}
Resumo: O rigor epistemológico da Terapia Ocupacional vem sendo questionado desde o seu surgimento, há quase um século. Ciência Ocupacional, uma nova disciplina que foi criada por terapeutas ocupacionais na América do Norte e desenvolveu-se principalmente no mundo anglo-saxão nos últimos 30 anos, tem produzido ampla discussão sobre os fundamentos teóricos e técnicos das intervenções baseadas na ocupação, além de estimular o debate internacional sobre as dimensões sociopolíticas dos vários modelos existentes. Este artigo, concebido como um ensaio reflexivo, objetiva rever os conceitos de ocupação e atividade tal como eles são apresentados na literatura anglófona contemporânea tanto da Terapia Ocupacional quanto da ciência ocupacional. Trabalhos científicos selecionados e documentos oficiais são discutidos. Após uma breve introdução que descreve o marco teórico que orienta a discussão, um resumo desses conceitos é apresentado. A análise leva em conta o desenvolvimento histórico das duas áreas e também procura destacar as oportunidades para a futura produção de conhecimento, tanto na Terapia Ocupacional como na ciência ocupacional.
\end{abstract}

Palavras-chave: Terapia Ocupacional, Ciência ocupacional, Terapia Ocupacional/tendências.

\section{Occupation and activity: trends and conceptual tensions in the Anglophone literature of occupational therapy and occupational science}

\begin{abstract}
The epistemological rigor of occupational therapy has been questioned since its emergence, nearly a century ago. Occupational science, a new discipline that was created by occupational therapists in North America and evolved mainly in the Anglo-Saxon world in the past 30 years, has produced extensive discussion about the theoretical and technical underpinnings of the occupation based interventions, besides stimulating the international debate on the socio-political dimensions of the various existing models. Designed as a reflective essay, this article aims to review the concepts of occupation and activity as they are presented in contemporary Anglophone literature of occupational therapy and occupational science. Selected scientific papers and official documents are discussed. After a brief introduction that describes the theoretical framework that guides the discussion, a summary of these concepts is presented. The analysis takes into account the historical development of the two areas and also seeks to highlight opportunities for the future production of knowledge, both in occupational therapy and occupational science.
\end{abstract}

Keywords: Occupational Therapy, Occupational Science, Occupational Therapy trends. 


\section{Introdução}

Lutar com palavras é a luta mais vã.

Carlos Drummond de Andrade, poema O lutador, A rosa do povo, 1945

Neste artigo, eu me proponho a contextualizar os conceitos de ocupação e atividade na perspectiva da literatura contemporânea da Terapia Ocupacional e da ciência ocupacional. Para isto, selecionei material publicado em inglês nas últimas décadas, mas de forma alguma diria que minhas escolhas foram sistemáticas ou neutras. Minha experiência como professora e pesquisadora brasileira trabalhando há uma década no Canadá certamente influenciou a minha percepção, mas meu intuito foi oferecer um panorama geral das principais tendências e tensóes nesses conceitos-chave das duas áreas. Após uma introduçáo que objetiva situar a discussão que se segue, apresento um sumário da conceituação de ocupação e de atividade na literatura anglófona contemporânea, buscando mostrar desdobramentos históricos, bem como apontar possibilidades para os próximos passos da produção intelectual da área.

Há quase cem anos, a ideia de um tratamento baseado nas atividades com as quais as pessoas se ocupam na sua rotina diária vem prosperando em várias partes do mundo. Esse modelo de intervenção, que a princípio pareceu absurdo ou romanticamente idealista (BING, 1981), resultou numa atividade profissional que é hoje exercida de modo regulamentado em pelo menos 73 países e conta com cerca de 350 mil profissionais em exercício, segundo a Federação Mundial dos Terapeutas Ocupacionais (WORLD..., 2013).

Um dos maiores problemas da internacionalização da profissão tem sido justamente a falta de clareza dos conceitos sugeridos, além das possibilidades concretas de traduçáo e disseminação internacional dos modelos de intervenção preconizados (MAGALHÃES, 2012; WRIGHT-ST CLAIR, 2012; RUDMAN et al., 2008).

No centro desse debate está a própria denominação da profissão: Terapia Ocupacional. Como vários autores destacam, a expressão ocupação (occupation) carrega significados dúbios no idioma inglês e nem sempre pode ser traduzida adequadamente para outros contextos linguísticos (MAGALHÂES; GALHEIGO, 2010; NELSON; JONSSON, 1999).

Um exemplo dessa diversidade é a denominação dos profissionais na Europa. Segundo o ENOTHE (European Network of Occupational Therapy in Higher Education), dos 19 países que qualificam profissionais atualmente, dez utilizam a expressão "ergotherapeut", seis países adotam o título terapeuta ocupacional e outros três usam palavras distintas como Idjuthjalfi, na Islândia, e Toimintaterapeutti, na Finlândia (EUROPEAN..., 2013). Essa diversidade, longe de beneficiar, pode criar sérias dificuldades para a identidade interna, mas também para a disseminação e reconhecimento externo da profissão (ROYEEN, 2002).

A relação entre linguagem e poder tem sido reconhecida, mas talvez não receba a devida atenção de pesquisadores e profissionais em geral, sobretudo na área de Terapia Ocupacional. Como assinalou o britânico Norman Fairclough (1989), investigar a relação entre linguagem e opressão teria o benefício de "ajudar a aumentar a consciência sobre como a linguagem contribui na dominação de alguns sobre os demais, porque essa consciência é o primeiro passo na direção da emancipação" (p. 1). Mais perto da realidade brasileira, Paulo Freire refletiu profundamente sobre a relação entre linguagem e opressáo. Para ele: "Mudar a linguagem faz parte do processo de mudar o mundo. A relação entre linguagem-pensamento-mundo é uma relação dialética, processual, contraditória" (FREIRE, 2008, p. 68). Freire nos chama ainda a atenção para a proverbial distância entre a fala do povo, do homem da rua, e a fala da ciência, que se quer objetiva, neutra e sofisticada. Freire e Shor sustentam:

Existe grande diferença, a que já me referi em nossos diálogos, entre a semântica e a sintaxe que usamos, enquanto intelectuais, na academia, e a sintaxe que ouvimos na fala das pessoas comuns, dos camponeses e da classe operária. Há diferenças marcantes entre as duas formas de linguagem. Ao mesmo tempo, essas diferenças não nos permitem, enquanto intelectuais, dizer que o discurso popular não tem capacidade de abstraçáo (SHOR; FREIRE, 1987, p. 179).

No caso da nossa profissão, essa reflexão assume extrema importância na medida em que, segundo Charles Christiansen (2006, p. XIII, original em inglês, tradução nossa), "a terapia ocupacional é, de modo bastante singular, uma profissão onde os mundos da ciência aplicada e da experiência de vida foram capazes de se unir".

Além disso, especialmente numa profissão de saúde que lida predominantemente com os despossuídos e os vulneráveis (MAGALHĀES, 1989; KRONENBERG; POLLARD, 2006; THIBEAULT, 2002), há que se considerar que:

[...] o uso deliberado da linguagem é um método facilitador para que aqueles que têm 
pouco poder de tomar medidas para mudar o pensamento dominante possam agir. [...] Em essência, a linguagem profissional constitui o discurso em torno do qual o poder profissional é organizado (TOWNSEND, 1998, p. 46, original em inglês, tradução nossa).

Portanto, refletir sobre as várias nomenclaturas, e (in)definições que a profissão adota, torna-se também um meio de pensar sobre nossos modos particulares de conhecer e valorar o conhecimento e de tentar identificar de que maneira as palavras condicionam (e revelam ou dissimulam) formas de pensar e agir. Cabe ainda investigar de que modo tudo isso vem se alterando, voluntária ou involuntariamente, no curso da história de nossa profissão.

\section{Diversidade, ambuiguidade, conformidade: muito além das palavras, um jeito de conceber e atuar no mundo}

Palavra dócil

Palavra d'água pra qualquer moldura

Que se acomoda em balde, em verso, em mágoa

Qualquer feição de se manter palavra

Chico Buarque, Uma palavra, 1995

Barreiras linguísticas na uniformização de terminologias profissionais são extensamente conhecidas e náo seria diferente na área de Terapia Ocupacional (MAGALHĀES; GALHEIGO, 2010). O conceito de ocupação exibe inúmeras e, às vezes, contraditórias definiçôes (PIERCE, 2001; ROYEEN, 2002). Além disso, Kantartzis e Molineux (2012) assinalam que o conceito tem se baseado prioritariamente em premissas que estão articuladas a partir de um estilo de vida associado a uma ideologia de classe média branca, economicamente estável e pautada por valores hegemônicos em países ocidentais. Por seu turno, Ramugondo e Kronenberg (2013, p. 3, original em inglês, tradução nossa) admitem que uma definição universal de ocupação é improvável, mas sustentam que devemos buscar a pluralidade de perspectivas culturais, "incluindo ontologias e epistemologias do Sul”. Não obstante, a Sociedade Internacional de Ciência Ocupacional (ISOS) usa termos bem gerais para definir ocupação:

as várias atividades cotidianas que as pessoas realizam como indivíduos, em família e nas comunidades, para ocupar seu tempo e trazer significado e propósito à vida. Ocupaçóes incluem coisas que as pessoas precisam, querem e espera-se que façam (INTERNATIONAL..., 2013).

Essa definição exibe uma característica que vale detalhar: a adoção da noção de significado (meaning, em inglês), que possui extrema importância para a maioria das publicaçóes relacionadas com a área. De fato, a preponderância do significado na qualificação da ocupação humana gerou a expressão being, doing, becoming, em inglês, (aproximadamente poderíamos traduzi-la como ser, fazer e transformar-se). Num texto que se tornou seminal, tanto para a Terapia Ocupacional quanto para a ciência ocupacional, Wilcock (1999, p. 3, original em inglês, traduçáo nossa) esboçou as bases de um extenso arcabouço teórico destinado a estabelecer a relação entre o fazer e o bem-estar: "Fazer e não fazer são poderosos determinantes do bem-estar ou da doença”. Entretanto, na visão da autora, para ser saudável, o fazer humano deve estar acompanhado da criação, da emoção e da aventura:

Em termos ocupacionais, o bem-estar através do fazer envolve acreditar que a gama potencial das ocupaçóes das pessoas permitirá a cada uma delas ser criativa, aventurar-se e encontrar sentido nas emoçôes humanas que experimentarem e explorarem no seu fazer. Significa ainda adaptar-se de forma adequada e sem interrupção indevida para atender, através do seu fazer, ao que suas vidas demandem (WILCOCK, 2006, p. 139, original em inglês, tradução nossa).

O tema da ocupação como um determinante de saúde informa vários trabalhos tanto na área de ciência ocupacional quanto na Terapia Ocupacional. Assim, o estabelecimento de uma estreita relaçáo entre significado (meaning), fazer, ser, transformação e saúde justifica a emergência de modelos de análise e intervenção a partir de uma ocupação que agora se torna qualificada como condição sine qua non de inclusão social, de saúde e de bem-estar (WILCOCK, 2007). Nesta perspectiva, nem todas as ocupaçóes seriam benéficas à saúde, apenas aquelas que possuem um inegável significado para o indivíduo ou sua comunidade. Vale assinalar, entretanto, que críticas têm sido feitas ao predomínio de uma visão otimista sobre a ocupação humana, ou seja, aos que sustentam que ocupaçóes são sempre benéficas para a saúde, o que é bastante comum na literatura profissional (KIEPEK; MAGALHAES, 2011).

Voltando ao conceito de ocupação e suas ambiguidades, permanece improvável a adoção de um conceito inequívoco, tanto para os modelos de 
intervenção baseados na ocupação quanto para a pesquisa, apesar dos inúmeros esforços de eminentes teóricos da área (JONSSON, 2008; PIERCE, 2009; ROYEEN, 2002).

É razoável supor que vários condicionantes podem ter determinado a vulnerabilidade conceitual apontada por tantos na Terapia Ocupacional, bem como na ciência ocupacional. Os estudiosos argumentam, por exemplo, que a utilização da palavra atividade como sinônimo de ocupação traz inúmeros problemas e precisa ser eliminada (NELSON, 1997) ou diligentemente redefinida (PIERCE, 2001). Com efeito, a expressão atividade tem sido, se não evitada, pelo menos secundarizada nos documentos oficiais, como se pode observar neste excerto da recente definição oficial da Federação Mundial dos Terapeutas Ocupacionais:

Terapia ocupacional é uma profissão de saúde centrada no cliente, preocupada em promover a saúde e o bem-estar através da ocupação. $\mathrm{O}$ principal objetivo da Terapia Ocupacional é facilitar a participação das pessoas em suas atividades diárias. Terapeutas ocupacionais alcançam esse objetivo trabalhando com indivíduos e comunidades para enriquecer suas possibilidades de engajamento em ocupações que eles querem, precisam ou espera-se que façam, seja pela modificação da ocupação ou dos ambientes, para facilitar e dar suporte ao seu engajamento ocupacional (WORLD..., 2012, original em inglês, tradução nossa).

Como se observa nessa definição, a expressão atividade jamais é utilizada, além de ser clara a ênfase no engajamento de pessoas e comunidades em suas atividades cotidianas, evitando citar eventuais "problemas clínicos" ou "deficiências". O texto aponta claramente para um modelo de intervenção que acentua o empoderamento de indivíduos e comunidades através do suporte do terapeuta ocupacional, que deixa de "prescrever atividades" e passa a facilitar a participação (tradução aproximada do verbo inglês to enable).

Cabe notar, no entanto, que ainda que a atual definição internacional da Terapia Ocupacional seja expressa em termos objetivos e pretensamente neutros, acadêmicos insistem em mostrar que, mesmo no idioma inglês, a palavra ocupação permanece um vocábulo ambíguo, que pode não gerar dúvidas dentro da comunidade profissional (o que está longe de ser verdade), mas se mantém obscura e imprecisa para o público em geral, para outros profissionais de saúde e para financiadores dos sistemas de saúde, entre outros (ROYEEN, 2002). De fato, Charlotte Royeen, uma professora de Nebrasca, nos Estados
Unidos, reconhecida entusiasta da rediscussão do termo ocupação, condiciona o fortalecimento da Terapia Ocupacional ao necessário esclarecimento das diferenças entre as expressôes atividade e ocupação, além da opção inequívoca por um modelo profissional baseado na ocupação, diligentemente definida. Royeen mostra que, entre os terapeutas ocupacionais, além da confusão com o termo atividade, a palavra ocupação frequentemente significa os meios pelos quais o terapeuta ocupacional trabalha, mas outras vezes também remete à finalidade, aos fins da própria intervenção. Diz ela:

Atividade significa ser ativo (de acordo com os dicionários). Talvez seja tempo de a Terapia Ocupacional servir melhor à sociedade concebendo a atividade como resultado do processo ocupacional [...] em termos mais claros, atividade e participação devem ser os resultados observáveis do processo de ocupaçáo... ocupação como meio de mudança é a força da profissáo e devemos promovê-la... Uma radical mudança no uso das palavras pelos terapeutas ocupacionais poderia ajudar a cristalizar a sua face pública para o mundo (ROYEEN, 2002, p. 116-7, original em inglês, tradução nossa).

Portanto, a distinção entre ocupação como fim ou objetivo último da intervenção terapêutica e ocupação como modalidade, ou meio de intervenção, está no centro do debate e, de certo modo, no centro das mudanças nos próprios modelos adotados.

Apesar disso, pelo menos um componente do chamado fazer humano permanece vinculado à expressão atividade, mesmo entre os anglófonos: as atividades da vida diária (daily life activities $-A D L$, em inglês). Embora seja clara a intenção de direcionar a terminologia na perspectiva da ocupação, o documento da WFOT assinala:

que o foco principal da Terapia Ocupacional é a ocupação, que inclui as atividades da vida diária mas náo se limita a ela, e reconhece essa área importante de especialidade dos terapeutas ocupacionais... Terapeutas ocupacionais são considerados peritos em ocupação e por extensão em AVD porque... eles possuem qualificação específica no uso de instrumentos de medida e intervenção para facilitar que indivíduos, com ou sem limitaçóes, participem nas ocupaçóes da vida diária, incluindo as atividades da vida diária (WORLD..., 2012, original em inglês, tradução nossa).

Reconhecendo que o assunto é controverso, o documento sugere ainda que há pelo menos duas formas de compreender as AVD: alguns as definem a 
partir de seu propósito, como no caso do autocuidado, do lazer e da produtividade. Por outro lado, há os que as concebem como atividades orientadas à interação com o ambiente, que frequentemente possue uma natureza complexa. Para superar a referida ambiguidade conceitual, a WFOT recomenda que os profissionais: "adotem terminologias baseadas na expressão ocupação em todas as suas comunicaçôes orais e escritas" (WORLD..., 2012, p. 2, original em inglês, tradução nossa).

Assim, longe de ser espontânea, a progressiva substituição da palavra atividade pela expressão ocupação nos documentos que orientam internacionalmente tanto o ensino quanto a prática dos terapeutas ocupacionais, pelo menos nos países de língua inglesa, tem sido não só planejada, mas acompanhada de intensa atividade de pesquisa e debate. Para se ter uma ideia, em 2002, no seu artigo, Royeen já assinalava 19 definiçóes diferentes para a expressão ocupação na literatura da área de Terapia Ocupacional naquele idioma.

A despeito da referida ambiguidade, a expressão ocupação, portanto, passa a ser sugerida como ponto de partida para o aprofundamento das bases científicas da profissão, consolidada a partir de duas estratégias principais: o modelo de intervenção centrado em evidências (LAW; BAUM, 1998) e o estudo sistemático da complexidade da ocupação humana e sua aplicabilidade aos processos terapêuticos e de mudança social (PRODINGER; STAMM, 2012). A primeira estratégia promoverá o surgimento de um instrumental científico sem precedentes na Terapia Ocupacional, principalmente anglo-saxá, notadamente na área de instrumentos de avaliação e artefatos técnicos de intervenção. A segunda corrente determinará o nascimento de uma nova disciplina teórica no campo das humanidades, que sumarizamos a seguir.

\section{Em busca de conhecimento} e sistematização do fazer, chegamos à própria complexidade da ocupação humana: a contribuição da
ciência ocupacional

A intenção de construir uma Terapia Ocupacional rigorosa no trato do seu objeto, a ocupação humana, levou a norte-americana Elizabeth Yerxa a propor, no início dos anos 1990, a criação de uma disciplina que levaria o nome Ciência Ocupacional e seria uma "ciência básica dedicada ao estudo dos humanos como seres ocupacionais" (YERXA, 1993, p. 5, original em inglês, traduçáo nossa).
Náo se pode dizer que esse projeto, ainda que exitoso, tenha acontecido sem crises ou tensões (HOCKING, 2000; HOCKING; NICHOLSON, 2007). A começar pela denominação, a nova disciplina suscitou debates:

ciência deve ser o nome de escolha para a ciência ocupacional ou a disciplina deveria ser renomeada para algo mais amplo, como investigação ocupacional (estudo da ocupação)? Certamente, se ciência significar uma ciência holística [...] o termo é apropriado. Entretanto, se ciência for definida como um pensamento estreito, reducionista, então a expressão não é apropriada (YERXA, 2009, p. 495, original em inglês, traduçáo nossa).

A institucionalização da ciência ocupacional tem sido inegável. Um estudo apontou, em 2009, dez organizaçóes que congregavam cientistas ocupacionais (PRODINGER; STAMM, 2012). Simpósios, seminários, grupos de discussão on-line têm sido realizados em diversas partes do globo, notadamente na América do Norte, Europa e Austrália. Já há programas educacionais desde o bacharelado até o doutorado. Pelo menos um periódico internacional, com base na Austrália, publica exclusivamente artigos na área de ciência ocupacional desde 1993 (Journal of Occupational Science - JOS), além de outras publicaçóes que também divulgam as pesquisas e os debates em curso (GLOVER, 2009; PIERCE et al., 2010).

Por razôes de espaço seria impossível sumarizar aqui os processos históricos que compóem o inegável fortalecimento da ciência ocupacional desde a sua criação (MAGALHÂES, 2012; PIERCE et al., 2010; PRODINGER; STAMM, 2012), mas é fácil notar que os estudos que aprofundam a compreensão da natureza complexa e multifacetada da ocupação humana estáo na linha de frente dos vários campos de pesquisa da ciência ocupacional e que, paralelamente, a expressáo atividade vai merecendo cada vez menos atenção dos pesquisadores, agora intitulados cientistas ocupacionais.

\section{Tensões internas e externas no campo da ciência ocupacional: a ocupação repartida, questionada, medida, desvendada, inatingível...}

A despeito do vertiginoso crescimento em menos de três décadas, a ciência ocupacional tem provocado intensos debates, tanto no interior da comunidade 
de terapeutas ocupacionais quanto entre os próprios cientistas ocupacionais, com fervorosos defensores, mas também com críticos contumazes. Morley, Atwal e Spiliotopoulou (2011), por exemplo, questionam a eficácia da contribuição da ciência ocupacional para programas de Terapia Ocupacional no Reino Unido. Os autores acreditam que verbas reduzidas de pesquisa tornaram-se ainda menores com o advento da ciência ocupacional e que a Terapia Ocupacional náo chegaria a se beneficiar de pesquisas que são realizadas a partir de paradigmas qualitativos el ou que náo enfatizam os modelos baseados em evidências, como os comumente adotados em ciência ocupacional.

Evidentemente, a criação de uma nova disciplina de estudos gera a necessidade de apropriação de recursos metodológicos alinhados com os valores e objetivos da nova área de estudo. Com efeito, é forçoso reconhecer que as metodologias influenciam diretamente o tipo de conhecimento produzido, bem como seu status científico. Farta discussão sobre as metodologias mais adequadas para a investigação dos processos ocupacionais tem sido produzida (KINSELLA, 2012; WRIGHT-ST CLAIR, 2012) mas, sendo esse tópico, todavia, fora do escopo deste trabalho, quero destacar que também na questão metodológica a pluralidade é sugerida como a forma mais efetiva de alcançarmos um conhecimento capaz de reconhecer e legitimar as diferenças sem estabelecer hierarquias (KRONENBERG; POLLARD; RAMUGONDO, 2011).

Voltando às tensões conceituais, ofereço um exemplo de um ponto de fricção e debate na produção contemporânea da ciência ocupacional: a polêmica entre o acento individualista, tanto da Terapia Ocupacional quanto da ciência ocupacional.

\section{Ocupar: eu ocupo, eu me ocupo, eu e você nos ocupamos, estamos ocupados, somos ocupados...}

O verbo ocupar, tanto em português como em inglês, tem características gramaticais especiais, que lhe emprestam significados e usos distintos. Por exemplo, trata-se de verbo transitivo direto, portanto podemos falar em ocupar algo ou algum lugar - "Ele ocupa o tempo com algo útil" - e pode ainda ser pronominal: "A linguística ocupa-se da linguagem humana em seus diversos aspectos". Esses exemplos nos mostram que se trata de vocábulo complexo, com múltiplas possibilidades, o que pode enriquecer os conceitos, mas também pode torná-los ambíguos, fluidos, flexíveis demais. Evidentemente, há outros condicionantes para isso, como os aspectos culturais, que têm sido amplamente discutidos e que, segundo alguns, náo foram ainda merecedores da devida atenção (IWAMA, 2006).

Assim, por exemplo, os aspectos culturais talvez expliquem o extenso debate travado em torno da questão do suposto individualismo dos modelos preconizados (ROZARIO, 1997), tanto na Terapia Ocupacional quanto na ciência ocupacional. Barber (2006) qualifica essa perspectiva como a ciência ocupacional na primeira pessoa. Segundo o autor, essa perspectiva deve-se à tradição fenomenológica de interpretação da experiência ocupacional como algo pessoal, situado na dimensão individual. A proposição suscitou uma série de artigos e respostas que foram publicados pelo Journal of Occupational Science (CUTCHIN; DICKIE; HUMPHRY, 2006; FOGELBERG; FRAUWIRTH, 2010). De modo geral, os artigos contêm diversas perspectivas filosóficas, mas há também materiais que assumem posicionamentos políticos, que buscam apontar o compromisso dos cientistas ocupacionais (e em certo sentido dos terapeutas ocupacionais) com abordagens predominantemente individualistas, marcadas por compromissos políticos e culturais nem sempre assumidos. $\mathrm{Na}$ verdade, esses críticos propóem que esses valores se alinhem a um projeto social marcado por projetos hegemônicos no ocidente, que dificilmente poderiam ser considerados universais (KANTARTZIS; MOLINEUX, 2012). Na mesma linha de argumentos, nota-se o surgimento de um campo de discussáo que privilegia a chamada co-ocupação (ocupação partilhada) como tema de análise (PICKENS; PIZUR-BARNEKOW, 2009; PIERCE, 2009).

A interatividade da ocupação, isto é, sua dimensão social transitiva, vai sendo investigada na esperança de trazer luz aos componentes que levam os indivíduos a escolher essa ou aquela ocupação (ou aceitá-la quando imposta), a realizá-las coletivamente, bem como o que leva as sociedades a considerar algumas ocupaçóes desejáveis enquanto outras serão liminarmente condenadas (KIEPEK; MAGALHAES, 2011). Por outro lado, Ramugondo e Kronenberg (2013) sustentam que compreender os aspectos coletivos da ocupaçáo humana e seus condicionantes socioambientais é condição para uma disciplina socialmente relevante e moralmente defensável. Partindo de exemplos retirados da experiência sul-africana de ocupaçóes coletivamente estruturadas, a partir de uma ética comportamental chamada ubantu, os autores mostram a necessidade de se superar a dicotomia individual-coletivo, bem como 
de valorizar-se a intencionalidade na conceituação das ocupaçôes humanas. O fazer coletivo, os autores argumentam, possui atributos emancipatórios que demandam teorizaçấo. Os autores então propóem para o debate uma definição das ocupaçôes coletivas:

[...] ocupaçôes nas quais os indivíduos, grupos e comunidades se engajam nos seu contexto cotidiano; que podem refletir propósitos de coesão ou disfunção social, bem como a proposição em favor ou em contrário ao bem comum [...] (RAMUGONDO; KRONENBERG, 2013, p. 8, original em inglês, tradução nossa).

Essa discussão, reconhecem os autores, está longe de ser concluída, mas precisa superar a usual dicotomia indivíduo-coletivo para alcançar um entendimento mais integral (holístico) do fazer humano.

\section{Próximos passos}

Uma criatura de nervos modernos, de inteligência sem cortinas, de sensibilidade acordada, tem a obrigação cerebral de mudar de opiniäo e de certeza várias vezes ao mesmo dia.

Fernando Pessoa, Crônica da vida que passa, 1915 (apud PESSOA, 1995)

Procurei sumarizar aqui os principais movimentos que a comunidade acadêmica, bem como os profissionais que focalizam a ocupaçáo como objeto de intervenção, têm realizado na direção de superar uma certa fragilidade conceitual muito frequente tanto na área de Terapia Ocupacional quanto na ciência ocupacional, a partir de material publicado no idioma inglês. A compreensão da ocupação humana e seus condicionantes sociais, econômicos, culturais, políticos etc., como procuramos mostrar, é o principal objeto da recém-criada ciência ocupacional. Essa disciplina vem se institucionalizando rapidamente e hoje conta com inúmeros centros de produçáo de conhecimento, notadamente em países de língua inglesa. Apesar de dificuldades na comunicação de parte a parte (entre cientistas ocupacionais e terapeutas ocupacionais), muitos têm identificado influências positivas da nova área de estudos nas práticas de intervenção propostas por terapeutas ocupacionais envolvidos no estudo da ocupação (LUNT, 1997).

Do ponto de vista da necessidade de aprimoramento conceitual que, na verdade, foi um dos determinantes que influenciaram a própria criação da ciência ocupacional, certamente não se pode dizer que a nova disciplina de estudo tenha sido capaz de eliminá-la. Ao contrário, é da capacidade de tolerar incertezas que o nosso trabalho poderá frutificar (KRONENBERG; POLLARD; RAMUGONDO, 2011). Não obstante, várias linhas de trabalho têm sido criadas e, pelo menos entre os anglófonos, a estabilidade na produção bibliográfica é uma indicação clara de promissora evolução. Um dos poucos consensos na produção anglófona aponta para a necessidade de superar dicotomias reducionistas e sugere a incorporação de metodologias inovadoras e multifacetadas, assumidamente ocupacionais (WRIGHT-ST CLAIR, 2012).

Um ponto a considerar, no entanto, é que a própria produção de conhecimento na área deve estar ancorada em contínuo escrutínio. Isto porque, conforme mostraram Kinsella (2012) e Valerie Wright-St Clair (2012), na própria concepção do que seja conhecimento válido, legítimo, sustentável residem as condiçóes de desenvolvimento de qualquer área de estudos. O potencial emancipatório desse conhecimento dependerá, no entanto, de escolhas éticas e morais que os profissionais precisam (e devem) fazer. Entretanto, como espero ter deixado claro, com seus múltiplos condicionantes, a ocupação constitui um objeto de extrema complexidade, que não somente requer uma perspectiva verdadeiramente plural e democrática mas também um refinado conjunto de instrumentos de análise, necessariamente interdisciplinar. As certezas e verdades absolutas serão muito provavelmente impossíveis e, como adverte Clare Hocking (2012, p. 61, original em inglês, tradução nossa):

Atingir o objetivo de gerar conhecimento que náo seja individualista, sexista, ou elitista vai requerer uma mudança de mentalidade, das ideias que combinam perfeitamente com valores de classe média - trabalhar duro e cuidar de si mesmo, para pesquisadores assumindo um papel ativo e responsável com relação às comunidades com as quais eles interagem.

Do mesmo modo, terapeutas ocupacionais têm diante de si a extraordinária tarefa de maximizar as possibilidades ocupacionais de indivíduos e grupos com os quais trabalham, a partir do reconhecimento do enorme potencial da ocupação criativa, significativa e transformadora.

Espero que este sumário possa compor um diálogo franco não apenas sobre a trajetória conceitual de ocupação e da atividade em vários contextos nacionais e no plano internacional, mas também sobre as possibilidades concretas de parcerias intelectuais e técnicas que conduzam à transformação 
dos fundamentos de nossas práticas através da compreensão de sua complexidade. Em última instância, nosso desafio é articular os múltiplos aspectos que podem conduzir à ampliação das oportunidades ocupacionais das populaçóes a quem nossas práticas se destinam.

Mesmo para compreender apenas uma vida, você precisa sorver o mundo.

Salman Rushdie, Midnight's Children, 1995

\section{Referências}

ANDRADE, C. D. A Rosa do Povo. Rio de Janeiro: José Olympio, 1945.

BARBER, M. Occupational Science and the FirstPerson Perspective. Journal of Occupational Science, Sidney, v. 4, n. 13, p. 94-96, 2006. http://dx.doi. org/10.1080/14427591.2006

BING, R. Occupational Therapy Revisited: A Paraphrastic Journey (1981 Eleanor Clarke Slagle Lecture). American Journal of Occupational Therapy, New York, v. 35, p. 499-518, 1981. Disponível em: <http://www.aota. org/Practitioners/Resources/Slagle/1981.aspx >. Acesso em: 6 maio 2013.

BUARQUE, C. Uma palavra. Interprete: Chico Buarque. In: BUARQUE, C. Uma palavra. [s.l.]: BMG International, 1995. Audio CD. Faixa 15.

CHRISTIANSEN, C. Foreword. In: IWAMA, M. The Kawa Model - culturally relevant occupational therapy. London: Elsevier Limited, 2006. p. XI-XIV. http://dx.doi. org/10.1016/B978-0-443-10234-9.50004-9

CUTCHIN, M. P.; DICKIE, V.; HUMPHRY, R. Transaction versus Interpretation, or Transaction and Interpretation? A Response to Michael Barber. Journal of Occupational Science, Sidney, v. 13, n. 1, p. 97-99, 2006. http://dx.doi.org/10.1080/14427591.2006.9686575

EUROPEAN NETWORK OF OCCUPATIONAL THERAPY IN HIGHER EDUCATION - ENOTHE. Education: Facts and figures relating to occupational therapy in Europe. [s.l.]: ENOTHE, 2013. Disponível em: <http://www.enothe.eu/index.php?page=about/ facts_and_figures>. Acesso em: 25 mar. 2013.

FAIRCLOUGH, N. Language and Power. London: Longman, 1989.

FOGELBERG, D.; FRAUWIRTH, S. A complexity science approach to occupation: Moving beyond the individual. Journal of Occupational Science, Sidney, v. 17, n. 3, p. 131-139, 2010. http://dx.doi.org/10.1080/14427 591.2010.9686687

FREIRE, P. Pedagogia da Esperança: um reencontro com a Pedagogia do Oprimido. 15. ed. São Paulo: Paz e Terra, 2008.

GLOVER, J. The literature of occupational science: A systematic, quantitative examination of peer-reviewed publications from 1996-2006. Journal of Occupational
Science, Sidney, v. 16, n. 2, p. 92-103, 2009. http://dx.doi. org/10.1080/14427591.2009.9686648

HOCKING, C. Occupational science: A stock take of accumulated insights. Journal of Occupational Science, Sidney, v. 7, n. 2, p. 58-67, 2000.

HOCKING, C. Occupation through the looking glass: Reflecting on Occupational Scientists' ontological assumptions. In: WHITEFORD, G.; HOCKING, C. (Ed.). Occupational science: Society, inclusion, participation. Oxford: Blackwell Publishing Ltd.; 2012. p. 54-65. http:// dx.doi.org/10.1002/9781118281581.ch5

HOCKING, C.; NICHOLSON, E. Occupation for occupational therapists How far we will go? In: CREEK, J.; LAWSON-PORTER, A. (Ed.). Contemporary issues in occupational therapy: Reasoning and Reflection. West Sussex: John Wiley \& Sons Ltd., 2007. p. 41-54.

INTERNATIONAL SOCIETY OF OCCUPATIONAL SCIENCE - ISOS. 2013. Disponível em: <http://www. isoccsci.org>. Acesso em: 25 mar. 2013.

IWAMA, M. The Kawa model: Culturally relevant occupational therapy. Churchill Livingstone: Elsevier Press, 2006.

JONSSON, H. A New Direction in the Conceptualization and Categorization of Occupation. Journal of Occupational Science, Sidney, v. 15, n. 1, p. 3-8, 2008.

KANTARTZIS, S.; MOLINEUX, M. Understanding the discursive development of occupation: Historico-political perspectives. In: WHITEFORD, G.; HOCKING, C. (Ed.). Occupational science: Society, inclusion, participation. Oxford: Blackwell Publishing Ltd., 2012. p. 38-53.

KIEPEK, N.; MAGALHAES, L. Addictions and ImpulseControl Disorders as Occupation: A Selected Literature Review and Synthesis. Journal of Occupational Science, Sidney, v. 18, n. 3, p. 254-276, 2011. http://dx.doi.org/ $10.1080 / 14427591.2011 .581628$

KINSELLA, A. Knoweledge paradigms in Occupational Science: Pluralistic Perspetives. In: WHITEFORD, G.; HOCKING, C. (Ed.). Occupational science: Society, inclusion, participation. Oxford: Blackwell Publishing Ltd., 2012. p. 8-19. http://dx.doi.org/10.1002/9781118281581. ch2

KRONENBERG, F.; POLLARD, N. Political dimensions of occupation and the roles of occupational therapy. The American Journal of Occupational Therapy, v. 60, n. 6, p. 617-626, 2006. http://dx.doi.org/10.5014/ajot.60.6.617 KRONENBERG, F.; POLLARD, N.; RAMUGONDO, E. Introduction: courage to dance politics. In: KRONENBERG, F.; POLLARD, N.; SAKELLARIOU, D. Occupational therapy without borders: towards an ecology of occupation-based practices. 2nd ed. Edinburgh; New York: Elsevier, 2011. p. 1-13.

LAW, M.; BAUM, C. Evidence-based occupational therapy. Canadian Journal of Occupational Therapy, Ottawa, v. 65, p. 131-135, 1998. http://dx.doi. org/10.1177/000841749806500301

LUNT, A. Occupational science and occupational therapy: Negotiating the boundary between a discipline 
and a profession. Journal of Occupational Science, Sidney, v. 4, n. 2, p. 56-61, 1997. http://dx.doi.org/10.1080/144 27591.1997.9686421

MAGALHÃES, L. Os terapeutas ocupacionais no Brasil: sob o signo da contradição. 1989. 145 f. Dissertação (Mestrado em Educação)-Universidade Estadual de Campinas, Campinas, 1989. Disponível em: <http:// www.bibliotecadigital.unicamp.br/document/?code $=\mathrm{vt}$ ls000018172\&fd=y>. Acesso em: 6 de março de 2013.

MAGALHÃES, L. What would Paulo Freire think of Occupational Science? In: WHITEFORD, G.; HOCKING, C. (Ed.) Occupational science: Society, inclusion, participation Oxford: Blackwell Publishing Ltd., 2012. p. 8-19. http://dx.doi.org/10.1002/9781118281581. ch2

MAGALHĀES, L.; GALHEIGO, S. Enabling international communication among Brazilian occupational therapists: Seeking consensus on occupational terminology. Occupational Therapy International, London, v. 17, n. 3, p. 113-124, 2010. http://dx.doi.org/10.1002/ oti. 292

MORLEY, M.; ATWAL, A.; SPILIOTOPOULOU, G. Has occupational science taken away the occupational therapy evidence base? British Journal of Occupational Therapy, London, v. 74, n. 10, p. 494-497, 2011. http:// dx.doi.org/10.4276/030802211X13182481842065

NELSON, D. Why the profession of occupational therapy will flourish in the 21st century. American Journal of Occupational Therapy, New York, v. 51, n. 1, p. 11-24, 1997.

NELSON, D. L.; JONSSON, H. Occupational terms across languages and countries. Journal of Occupational Science, Sidney, v. 6, n. 1, p. 42-47, 1999.

PESSOA, F. Obra Poética. Rio de Janeiro: Editora Nova Aguilar, 1995. 112 p.

PICKENS, D. N.; KRIS PIZUR-BARNEKOW, K. Co-occupation: Extending the dialogue. Journal of Occupational Science, v. 16, n. 3, p. 151-156, 2009. http:// dx.doi.org/10.1080/14427591.2009.9686656

PIERCE, D. Untangling occupation and activity. American Journal of Occupational Therapy, New York, v. 55, n. 2, p. 138-146, 2001. http://dx.doi.org/10.1080/14427591 .2010 .9686697

PIERCE, D. Co-occupation: The challenges of defining concepts original to occupational science. Journal of Occupational Science, Sidney, v. 10, n. 16, p. 203-207, 2009. http://dx.doi.org/10.1080/14427591.2009.9686663

PIERCE, D. et al. Occupational science: A data-based American perspective. Journal of Occupational Science, Sidney, v. 17, n. 4, p. 204-215, 2010.

PRODINGER, B.; STAMM, T. The emergence of occupational science in Austria: An insider perspective. Journal of Occupational Science, Sidney, v. 19, n. 2, p. 127-137, 2012. http://dx.doi.org/10.1080/14427591 .2011 .582833

RAMUGONDO, E. L.; KRONENBERG, F. Explaining Collective Occupations from a Human Relations Perspective: Bridging the Individual-Collective Dichotomy.
Journal of Occupational Science, Sydney, 2013. Published online. http://dx.doi.org/10.1080/14427591.2013.781920 ROYEEN, C. Occupation reconsidered. Occupational Therapy International, London, v. 9, n. 2, p. 11-20, 2002. ROZARIO, L. Shifting paradigms: The transpersonal dimensions of ecology and occupation. Journal of Occupational Science, Sidney, v. 4, n. 3, p. 112-118, 1997.

RUDMAN, D. L. et al. A vision for occupational science: Reflecting on our disciplinary culture. Journal of Occupational Science, Sidney, v. 15, n. 3, p. 136-146, 2008. http://dx.doi.org/10.1080/14427591.2008.9686623

RUSHDIE, S. Midnight's children: A novel. [sl.1]: Penguin Books, 1995. $649 \mathrm{p}$.

SHOR, I.; FREIRE, P. A pedagogy for liberation: dialogues on transforming education. South Hadley: Bergin \& Garvey Publishers, Inc.,1987.

THIBEAULT, R. Occupation and the rebuilding of civil society: notes from the war zone, Journal of Occupational Science, Sidney, v. 9, n. 1, p. 38-47, 2002.

TOWNSEND, E. Occupational therapy language: Matters of respect, accountability and leadership. Canadian Journal of Occupational Therapy, Ottawa, v. 65, n. 1, p. 45-50, 1998. http://dx.doi.org/10.1177/000841749806500106

WILCOCK, A. A. Reflections on doing, being and becoming. Australian Occupational Therapy Journal, v. 46, p. 1-11, 1999. http://dx.doi. org/10.1046/j.1440-1630.1999.00174.x

WILCOCK, A. An occupational perspective of health. 2nd ed. Thorofare: Slack, 2006.

WILCOCK, A. A. Occupation and health: Are they one and the same? Journal of Occupational Science, Sidney, v. 14, n. 1, p. 3-8, 2007. http://dx.doi.org/10.1080/144 27591.2007.9686577

WORLD FEDERATION OF OCCUPATIONAL THERAPISTS - WFOT. Position Statement Activities of Daily Living. [s.1.]: WFOT, 2012. Disponível em: <http:// www.wfot.org/ResourceCentre/tabid/132/cid/31/Default. aspx>. Acesso em: 02 maio 2013.

WORLD FEDERATION OF OCCUPATIONAL THERAPISTS - WFOT. Statement on Occupatonal Therapy. [s.l.]: WFOT, 2013. Disponível em: <http://www. wfot.org/Portals/0/PDF/STATEMENT\%20ON\%20 OCCUPATIONAL\%20THERAPY\%20300811.pdf>. Acesso em: 02 maio 2013.

WRIGHT-ST CLAIR, V. A. The case for multiple research methodologies. In: WHITEFORD, G.; HOCKING, C. (Ed.). Occupational science: Society, inclusion, participation. Oxford: Blackwell Publishing Ltd., 2012. p. 138-151. http://dx.doi.org/10.1002/9781118281581.ch10

YERXA, E. J. Occupational science: A new source of power for participants in occupational therapy. Journal of Occupational Science, Sidney, v. 1, n. 1, p. 3-9, 1993.

YERXA, E. J. Infinite Distance between the I and the It. American Journal of Occupational Therapy, New York, v. 63, n. 4, p. 490-497, 2009. http://dx.doi.org/10.5014/ ajot.63.4.490 